\title{
Technological and Quality Aspects of the Use of Innovative Inorganic Binders in the Production of Castings
}

\author{
Tomáš Obzina ${ }^{1}$, Václav Merta ${ }^{1}{ }^{*}$, Martin Folta ${ }^{2}{ }^{\circledR}$, Josef Bradáč ${ }^{3}{ }^{(0)}$, Jaroslav Beňo ${ }^{1}$, Nikol Novohradská ${ }^{1}$, \\ Martina Gawronová ${ }^{1}$, Ivana Kroupová ${ }^{1}$, Petr Lichý ${ }^{1}$, Filip Radkovský ${ }^{1}$, Kamila Janovská ${ }^{1}$, Iveta Vasková ${ }^{4}$, \\ Klára Drobíková ${ }^{5}$ and Isabel Nguyenová ${ }^{6}$
}

1 Faculty of Materials Science and Technology, VSB-Technical University of Ostrava, 70800 Ostrava, Czech Republic; tomas.obzina@vsb.cz (T.O.); jaroslav.beno@vsb.cz (J.B.); nikol.novohradska@vsb.cz (N.N.); martina.gawronova@vsb.cz (M.G.); ivana.kroupova@vsb.cz (I.K.); petr.lichy@vsb.cz (P.L.); filip.radkovsky@vbs.cz (F.R.); kamila.janovska@vsb.cz (K.J.)

2 Department of Production, Logistics and Quality Management, ŠKODA AUTO University, 29301 Mladá Boleslav, Czech Republic; martin.folta@savs.cz

3 Department of Mechanical and Electrical Engineering, ŠKODA AUTO University, 29301 Mladá Boleslav, Czech Republic; josef.bradac@savs.cz

4 Faculty of Materials, Metallurgy and Recycling, Technical University of Košice, 04200 Košice, Slovakia; iveta.vaskova@tuke.sk

5 Nanotechnology Centre, CEET, VSB-Technical University of Ostrava, 70800 Ostrava, Czech Republic; klara.drobikova@vsb.cz

6 Brembo Czech, s.r.o., 72000 Ostrava, Czech Republic; Isabel_Nguyenova@cz.brembo.com

* Correspondence: vaclav.merta@vsb.cz; Tel.: +420-608-863-842

Citation: Obzina, T.; Merta, V.; Folta, M.; Bradáč, J.; Beňo, J.; Novohradská, N.; Gawronová, M.; Kroupová, I.;

Lichý, P.; Radkovský, F.; et al.

Technological and Quality Aspects of the Use of Innovative Inorganic Binders in the Production of Castings. Metals 2021, 11, 1779. https:// doi.org/10.3390/met11111779

Academic Editor: Alexander McLean

Received: 24 September 2021

Accepted: 2 November 2021

Published: 4 November 2021

Publisher's Note: MDPI stays neutral with regard to jurisdictional claims in published maps and institutional affiliations.

Copyright: (c) 2021 by the authors. Licensee MDPI, Basel, Switzerland. This article is an open access article distributed under the terms and conditions of the Creative Commons Attribution (CC BY) license (https:/ / creativecommons.org/licenses/by/ $4.0 /)$.
Abstract: The production of cores for the pre-casting of holes in castings places high demands on the quality of the molding mixtures used. For this reason, organic binders are still used to a large extent, which, although they meet the technological requirements, are a source of pollutant emissions during the production of castings. The current trend towards greening production is therefore looking for a suitable alternative in 'green' inorganic binders. Although for many decades standard inorganic binders could not be compared with organic resins in terms of technological properties, new inorganic binder systems are currently being developed that can largely eliminate these disadvantages, which include, in particular, significantly lower collapsibility and reclaimability, and lower mechanical strength values. Last but not least, the use of these binder systems may be limited by the technological parameter of shelf-life, which is the main focus of this study. The aim of this paper is to evaluate the influence of technological parameters of core production using a new generation of inorganic binder systems on their shelf-life. Shelf-life, defined as the change in mechanical strength and wear resistance as a function of exposure time in a given environment, is evaluated under different climatic conditions.

Keywords: foundry; inorganic binders; shelf-life; WARM-BOX; surface product quality

\section{Introduction}

Inorganic binder systems are an integral part of materials for the production of molds and cores in the production of cast components. The beginning of their application is connected with the Czechoslovak patent of Dr. Lev Petržela from 1947 [1]. This patent deals with the production of molds, resp. cores by the COLD-BOX method, where the basic mechanism is curing of the molding mixture with alkaline silicate with gaseous carbon dioxide. During following period, this technology was modified in many different ways, one of them is the alkaline silicate application as a binder in the molding mixture, which is cured by liquid esters [2,3].

This NO BAKE method is one of the most widespread technologies for the production of molds using inorganic binder systems. Although it is an environmentally friendly 
method of producing molds and cores (only water vapor and carbon oxides are released from the mold/cores during casting), their significant expansion has been prevented by a number of technological disadvantages in comparison with organic resin binder systems. The most significant disadvantage is deteriorated collapsibility of the molding mixture after casting. The formation of glass residues (melting of glass) on the grain surface leads to the fact, that significantly higher strength after casting is achieved than the primary strength (strength after curing). Another significant disadvantage resulting from glass residue formation could also be worsen ability to reclamation [4]. Generally, there is possibility to use limited amount of reclaim sand (50 to $85 \%$ ) depending on the type of reclamation equipment and reclamation method [5].

The mechanical properties (generally determined as transverse strength) of the mixtures, which are crucial mainly for the cores to withstand the casting process, are significantly lower. Although the dosage of alkali silicate binders is higher, typical transverse strength values for molding mixtures with inorganic binders are lower in comparison with organic binders. If, for example, alkaline silicate cured with liquid hardeners is used the typical transverse strength values range from 1.0 up to $1.4 \mathrm{MPa}$. On the other hand, if the system Furan NO BAKE is used, the typical transverse strength values vary from 1.8 up to 2.2 MPa. Generally, NO BAKE systems with inorganic binder works with binder dosage ranged from $2.5 \%$ up to $3.5 \%$ in comparison with $0.8-0.9 \%$ for Furan NO BAKE. In the case of the production of cores cured with carbon dioxide gas, the final strength of the core and its shelf-life are significantly different [6].

The production of castings is generally campaign-oriented. The production of molds and cores is also subject to this, which usually represents two different technological flows. The production of molds is usually simpler, especially in terms of logistics and preparation. On the other hand, the production of cores is much more complicated, when more time is needed for each manufactured item, especially in terms of preparation and replacement of the corebox, but also due to the need to optimize working conditions for core production such as curing time, shooting pressure, etc. Therefore, in order to ensure the production of castings in the sense of "just in time", it means for a particular casting to have the mold and core produced at a given time, it is advantageous to produce cores in stock and thus ensure their availability at any time. The cores stored in this way must still be of high quality, in the sense of sufficient mechanical strength, high wear resistance, etc. The time at which these properties fall below an acceptable level is generally referred to as their shelf-life.

From production practice it is known that the maximum shelf-life of cores is up to one week after cores manufacture, otherwise a significant degradation of the core (decrease of strength, reduction of wear resistance) is observed, which can lead to formation of various undesirable casting defects. On the other hand, for example if the organic resin is applied and the cores are produced by the COLD-BOX Amin (PUCB) method the cores shelf-life takes for couple of weeks when the required storage conditions are met. It is known from field practice that cores produced by the COLD-BOX (alkaline phenolic cured with gaseous $\mathrm{CO}_{2}$ ) method have a maximum shelf-life of about 4 days, cores produced by the COLD-BOX Amin (PUCB) method about 1 week, and RCS-based cores have an almost unlimited shelf-life. Another significant difference is the productivity of core production, which is generally expressed in terms of the number of cores produced per unit time, for example $1 \mathrm{~h}$. This parameter is highly variable based on the specific type of core produced and the number of produced cores in one production cycle (the multiplicity of corebox). Therefore, for easier comparison between individual technologies or used binder systems, a comparison based on the time of one production cycle is more appropriate, which ranges from seconds to tens of seconds for organically bonded molding mixtures.

A significant milestone in the development and application of inorganic binder systems is dated at the turn of the millennium, when new development ways in the field of inorganic binders began to be presented [7]. Firstly, it is the application of new types of inorganic materials (Hydrobond, Beach Box, salt cores), but also modified alkaline silicates. The basic principle of these technologies is the curing of alkaline silicate by the effect of 
heat, either with hot air or, for example, using microwaves. The curing reaction then runs according to the Equation (1).

$$
\mathrm{Na}_{2} \mathrm{O} \cdot \mathrm{mSiO}_{2} \cdot \mathrm{H}_{2} \mathrm{O}+\text { energy } \underset{+\mathrm{H}_{2} \mathrm{O}}{\stackrel{-\mathrm{H}_{2} \mathrm{O}}{\longrightarrow}} \mathrm{Na}_{2} \mathrm{O} \cdot \mathrm{mSiO}_{2}
$$

$\mathrm{Na}_{2} \mathrm{O} \cdot \mathrm{mSiO}_{2} \cdot \mathrm{nH}_{2} \mathrm{O}$ - sodium silicate hydrate.

$\mathrm{Na}_{2} \mathrm{O} \cdot \mathrm{mSiO}_{2}$-sodium silicate.

In contrast to traditional processes, the dehydration curing process of alkaline silicates results in significantly higher mechanical properties of molding mixtures, in this case determined as transverse strength, even at significantly lower binder dosages [8-10]. See the differences of transverse strength of molding mixtures using alkaline silicates binders cured by different methods in Figure 1, where the reference value 100\% means the strength value for "microwave" curing (marked as MV) of molding mixture with inorganic binder and reaches transverse strength of approximately $4 \mathrm{MPa}$.

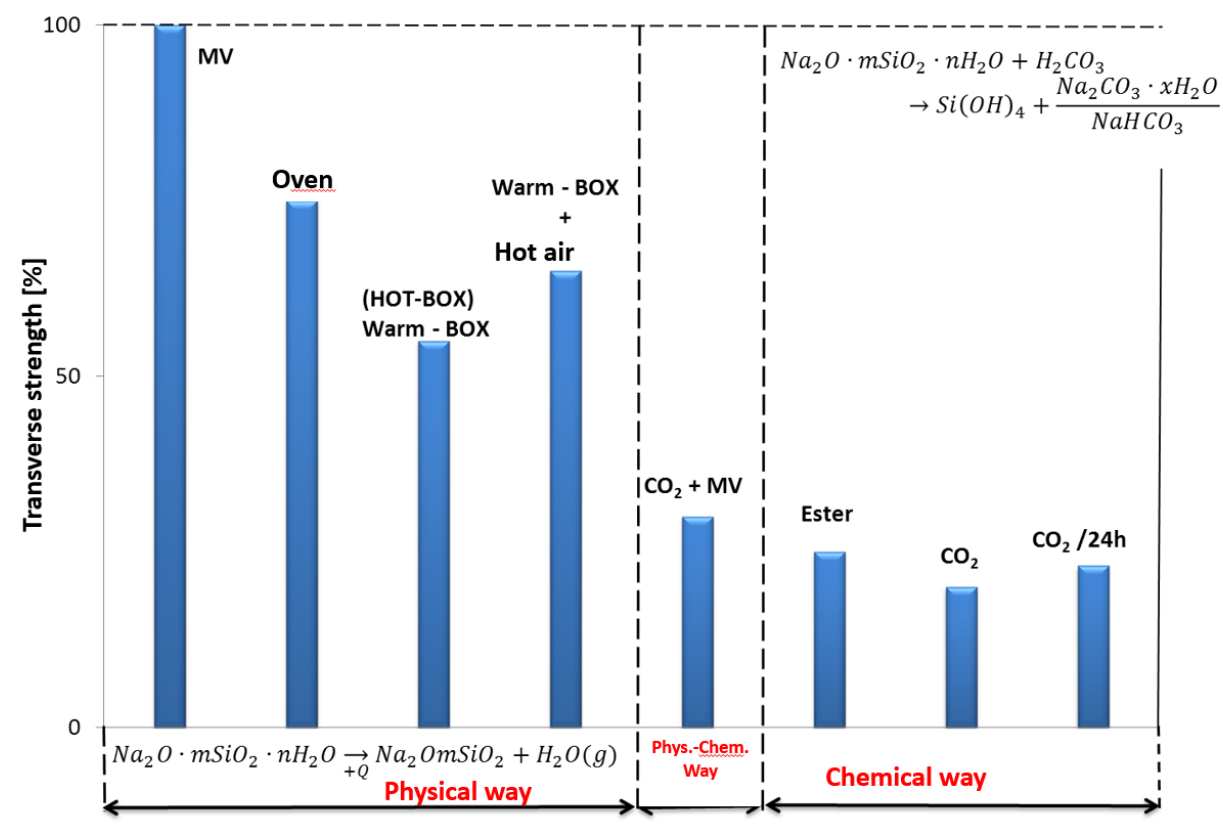

Figure 1. Transverse strength of molding mixtures using alkaline silicates binders cured by different methods [7].

This fact enables the production of complex and thin-walled cores typical for automotive production [11,12]. In addition, these technologies maintain their environmentally friendly nature, the collapsibility of the mixtures is improved during cores shaking-out (the possibility of combining mechanical shaking out of the cores with water rinsing) and, as a result of the lower binder content a reclaimability is also improved. The productivity of core manufacture is also increasing and the production cycle is approaching the speed of production of cores from mixtures with organic binders. In the dehydration process of curing inorganic binders, the rate of the curing reaction is given by the rate of suction of water vapor released from the cured binder. In general, thermosetting processes are, however, energy-intensive as well as increased costs for coreboxes and other accessories, because commonly used wood and other types of coreboxes cannot be used in comparison with the COLD-BOX core production method.

Another disadvantage of dehydration-cured cores is their shelf-life. In comparison with traditional alkaline silicates curing technologies (COLD-BOX, NO BAKE), where the final product of the curing reaction is a gel of silicic acid, thus this reaction is irreversible, the principle of the heat cured reaction is only dehydration of the binder itself. This reaction is reversible, so during the storage of the cores the binder is wetted back and 
thus the core itself degrades (decrease in the mechanical properties of the cores, including wear resistance).

The goal of this study is to determine the optimal conditions for extending the shelflife of cores produced from inorganic geopolymer precursor, which is cured by dehydration processes. The core transverse strength decrease of $20 \%$ was determined as a critical value and the time to achieve this value was than determined as maximal shelf-life under specific storage conditions. To obtain a more detailed understanding of the core rewetting process, the conditions of the core manufacturing process were also studied, more specifically shooting pressure, which may affect the shelf-life of dehydration-cured cores under the least suitable storage conditions. Furthermore, the influence of storage conditions of cores produced by dehydration processes on the actual surface quality of pre-cast holes were studied.

\section{Materials and Methods}

Due to the fact that thin walled and very complicated shape of cores (pre-cast holes, respectively) is required in automotive parts production, core mixtures based on NOVOLAK phenol-formaldehyde resins are mainly used in this specific production. This technology is known as a resin coated sand (RCS). As a possible alternative for RCS, the inorganic binder system GEOPOL ${ }^{\circledR}$ (product of SAND TEAM, spol. s r.o., Holubice, Czech Republic) was selected for this study. The binder is an inorganic geopolymer precursor with a low degree of polymerization. The hardening occurs by the action of heat or hardeners. There is an increase in the degree of polymerization and formation of an inorganic polymer during the hardening reaction. The GEOPOL ${ }^{\circledR}$ is odorless technology and generates no pollutants, so it has a minimal negative impact on the environment [13].

Following general parameters commonly used for characterization of core mixtures were determined:

1. Loss on ignition of dried samples $\left(105^{\circ} \mathrm{C}\right.$ up to constant weight $)$ at $900{ }^{\circ} \mathrm{C} / 2 \mathrm{~h}$,

2. $\mathrm{pH}$ and conductivity of water suspension (1:10 solid-liquid ratio),

3. Particle size distribution according to German standard VDG MERKBLATT P34.

Test specimens measuring $22.4 \mathrm{~mm} \times 22.4 \mathrm{~mm} \times 170 \mathrm{~mm}$ for determining the mechanical properties of mixtures with the studied binder were prepared on a laboratory shooting machine LUT (MULTISERW-Morek Jan Morek, Brzeźnica, Poland), in a triple corebox. The production parameters of test specimens for the determination of transverse strength and for the production of test cores are summarized in Table 1. The setting of process parameters for mixtures with geopolymer binders accords to the parameters recommended by the binder supplier, SAND TEAM, spol. s r.o.

Table 1. Parameters for the production of test specimens for the evaluation of mechanical properties of mixtures and test cores.

\begin{tabular}{cc}
\hline Parameters of Curing & $\begin{array}{c}\text { Binder System } \\
\text { Geopol }{ }^{\circledR}-\mathbf{W}\end{array}$ \\
\hline Corebox temperature & $150{ }^{\circ} \mathrm{C}$ \\
Shooting pressure & $6 \mathrm{bar}$ \\
Shooting Time & $6 \mathrm{~s}$ \\
Curing Time & $120 \mathrm{~s}$ \\
Amount of mixture in shooting head & $700 \mathrm{~g}$ \\
\hline
\end{tabular}

The middle core was used to determine hot transverse strength (measured immediately after preparation), the outer cores were used to determine cold transverse strength after $1 \mathrm{~h}$ from preparation. Transverse strengths were measured using universal testing machine, the LRU-2e type (MULTISERW-Morek Jan Morek, Brzeźnica, Poland). The core mixture for the production of test specimens was prepared on a batch mixer. The samples of the core mixtures with inorganic binder GEOPOL ${ }^{\circledR} \mathrm{W}$ were prepared by $1 \mathrm{~min}$ homogenization of the silica sand with powder additive, W308B, in the constant amount of $1 \%$ and 
then the constant amount $2 \%$ of the binder GEOPOL W20 were added to the mixture for further homogenization for another $1 \mathrm{~min}$.

It is generally known that exceeding the optimum shelf-life of cores not only results in a decrease in their mechanical strengths, but also in a decrease in wear resistance. These cores can then no longer be used for casting cavities and holes in the manufacture of cast components. The wear resistance was tested by placing the test specimen in a rotating wire cage drum and then tumbling it for $1 \mathrm{~min}$. The decrease in the weight of the test specimen, expressed as a percentage, was then determined as a measure of the wear resistance of the mixture. The moisture content (degree of hydration) of the samples during storage under defined conditions was also measured.

The shelf-life, defined as the change in mechanical properties (transverse strength and wear resistance) as a function of exposure time in the given environment, is evaluated under different climatic conditions (relative humidity " $\mathrm{RH}^{\prime}$ " and temperature " $\mathrm{t}$ ") according to changes of climatic conditions during individual year seasons:

- Laboratory ambient conditions- $\mathrm{RH}=60 \% \pm 5 \%, \mathrm{t}=25^{\circ} \mathrm{C}$ (marked as STANDARD)

- High $\mathrm{RH}$, constant temperature- $\mathrm{RH}=90 \% \pm 5 \%, \mathrm{t}=25^{\circ} \mathrm{C}$ (marked as HRH)

- Constant $\mathrm{RH}$, low temperature- $\mathrm{RH}=60 \% \pm 5 \%, \mathrm{t}=10{ }^{\circ} \mathrm{C}$ (marked as CRH)

- Low $\mathrm{RH}$, constant temperature- $\mathrm{RH}=10 \% \pm 5 \%, \mathrm{t}=25^{\circ} \mathrm{C}$ (marked as LRH)

The changes of transverse strength under individual condition mentioned above were determined after $1 \mathrm{~h}, 12 \mathrm{~h}, 24 \mathrm{~h}, 36 \mathrm{~h}, 48 \mathrm{~h}$ and $72 \mathrm{~h}$ after testing specimen manufacture and the decrease of strength higher than $20 \%$ was considered as a maximal shelf-life of the mixture.

Based on the evaluation of the influence of storage conditions on the mechanical properties of the cores (influence on shelf-life, respectively), the possibilities of influencing the shelf-life of heat-cured cores by changing the production parameters were further studied. Test specimens with defined dimensions of $22.4 \mathrm{~mm} \times 22.4 \mathrm{~mm} \times 170 \mathrm{~mm}$ for the determination of transverse strength were produced under the same conditions (see Table 1), only at different shooting pressures (8 and 10 bar). The effect of higher shooting pressure should be reflected by a change in the relative porosity of the sample and thus reduce the potential of the sample to rehydrate, as has been found previously for selected inorganic binders [14]. The relative porosity was determined according to the Equation (2).

$$
\mathrm{m}=\frac{\rho_{\mathrm{SiO}_{2}}-\rho_{\mathrm{CORE}}}{\rho_{\mathrm{SiO}_{2}}} \times 100 \%
$$

m-porosity.

$\rho_{\mathrm{SiO} 2}$-density of silica $\left(\mathrm{g} \cdot \mathrm{cm}^{-3}\right)$.

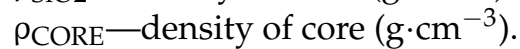

The influence of the change in shooting pressure on the decrease in transverse strength and wear resistance (respectively, on the shelf-life) of the studied samples, was monitored both under the conditions under which the most rapid degradation of the studied samples occurred and for comparison under standard (laboratory) conditions.

Furthermore, the effect of storage conditions on the surface quality of the precast holes from the cores studied was also studied for cores produced by dehydration processes. For these purposes, a special test casting with two cores, described in more detail below, was used. The surface quality was determined for samples produced at shooting pressures of 6 , 8 and 10 bar and stored for $24 \mathrm{~h}$ both under the conditions under which the most rapid degradation of the studied samples occurred and, again for comparison, under standard (laboratory) conditions.

A simple block-shaped test casting with two cores of square cross-section was designed for testing various core mixtures under real casting production conditions. It is intended mainly for testing the collapsibility of individual core mixtures, but it also serves very well for determining the influence of the tested core mixture on the surface quality of the casting. The test casting (see Figure 2) weighing $196 \mathrm{~g}$ (gross weight $401 \mathrm{~g}$ ) has an average 
wall thickness of $5.0 \mathrm{~mm}$ and dimensions of $32.5 \mathrm{~mm} \times 65 \mathrm{~mm} \times 60 \mathrm{~mm}$ and was designed to simulate the production of thin-walled castings with relatively massive cores. The test castings were cast from AlSi7Mg aluminum alloy at a constant casting temperature of $720 \pm 5{ }^{\circ} \mathrm{C}$ and a constant casting time of $4 \pm 0.5 \mathrm{~s}$.

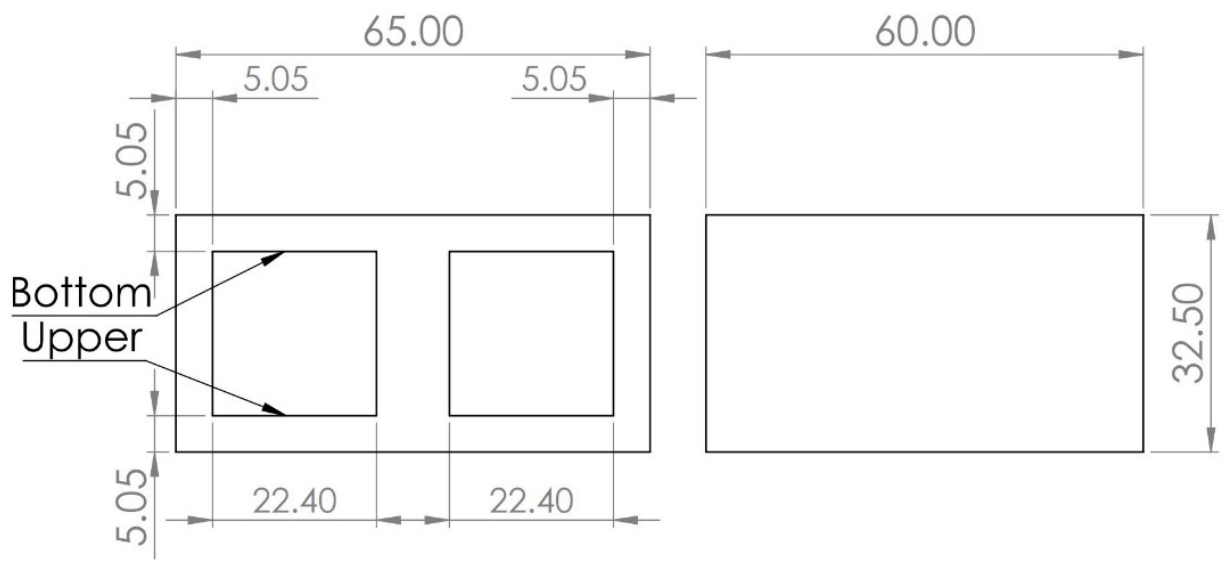

Figure 2. Test casting scheme.

The surface quality of test castings around cores with studied binder systems was determined using a bifocal digital microscope KEYENCE, VHX 6000 (Keyence, Ósaka, Japan). Photographs were taken at $500 \times$ magnification under coaxial light, also using the "stitching" function, on which the measurement of the mean arithmetic roughness Ra and the maximum peak to valley height of profile $\mathrm{Rz}$ determined from 10 points in accordance with the ISO standard EN ISO 4287 was performed. For the purpose of this measurement the test casting was cut in a half (horizontally) and the measurements were taken both on the upper and bottom surfaces of each individual cavity from the core to eliminate the possible influence of the different position of the measured surface in the casting. On each half, the roughness was determined for both surfaces from the cores at the three lengths evaluated (edge, center, edge). At each of these lengths, five sections were evaluated from which roughness values were obtained using the non-contact measurement method. The resulting surface roughness was then determined for each casting as the average of all 60 individual measurements (15 measurements on 4 surfaces). For the evaluation of the parameters $\mathrm{Ra}$ and $\mathrm{Rz}$ a range of $0.6<\mathrm{Ra}<2.0 \mu \mathrm{m}$ was chosen, $\lambda \mathrm{c}$ was chosen to be $0.8 \mathrm{~mm}$ and $\lambda \mathrm{s} 2.5 \mu \mathrm{m}$.

\section{Results}

At the start of the experiments basic parameters were evaluated. The basic parameters of the test mixture are summarized in Table 2.

Table 2. General parameters of studied core mixtures.

\begin{tabular}{lcc}
\hline Parameter & Unit & W303 \\
\hline Loss on ignition & $\%$ & 0.28 \\
$\mathrm{pH}$ & - & 10.71 \\
Conductivity & $\mu \mathrm{S} / \mathrm{cm}$ & 1159.0 \\
Medium grain size $\mathrm{d}_{50}$ & $\mathrm{Mm}$ & 0.24 \\
AFS. GN. & - & 57.77 \\
Degree of homogeneity S & $\%$ & 62.13 \\
Amount of fine particle (below $0.18 \mathrm{~mm})$ & $\%$ & 19.55 \\
\hline
\end{tabular}

${ }^{1}$ Calculated as the $d_{75} / d_{25}$ ratio.

The value of the loss on ignition of the test mixture is very low $(0.28 \%)$, which is due to the nature of the binder, which contains a high amount of water according to the type of binder. The alkaline character of the binder is then confirmed by the value of $\mathrm{pH}(10.71)$ and electrical conductivity $(1159 \mu \mathrm{S} / \mathrm{cm})$, which is typical for inorganic binder systems. 
The remaining parameters characterize the actual used silica sand (Biala Góra 27). The determined values of the medium grain size (d50), AFS GN, respectively, confirms that it is a sand suitable for the production of cores.

Individual test specimens made from the mixture described above were further stored under defined conditions. As a measure of the maximal shelf-life of the samples, it was determined a decrease in the mechanical properties of the test specimens by a maximum of $20 \%$ compared to the original cold transverse strength ( $1 \mathrm{~h}$ after sample preparation). The influence of storage conditions on the transverse strength of the test specimens is summarized in Table 3. The values in the table are the average of three measurements, therefore the value of the standard deviation is also given.

Table 3. Transverse strength with standard deviation [MPa] of studied cores stored under defined conditions: LRH-Low relative humidity, constant temperature- $\mathrm{RH}=10 \% \pm 5 \%, \mathrm{t}=25{ }^{\circ} \mathrm{C}$; STANDARD—Laboratory ambient conditions$\mathrm{RH}=60 \% \pm 5 \%, \mathrm{t}=25^{\circ} \mathrm{C} ; \mathrm{HRH}-$ High relative humidity, constant temperature- $\mathrm{RH}=90 \% \pm 5 \%, \mathrm{t}=25^{\circ} \mathrm{C} ; \mathrm{CRH}-$ Constant relative humidity, low temperature- $\mathrm{RH}=60 \% \pm 5 \%, \mathrm{t}=10{ }^{\circ} \mathrm{C}$.

\begin{tabular}{ccccccc}
\hline Conditions & $\mathbf{1 ~ h}$ & $\mathbf{1 2} \mathbf{h}$ & $\mathbf{2 4} \mathbf{h}$ & $\mathbf{3 6} \mathbf{h}$ & $\mathbf{4 8} \mathbf{h}$ & $\mathbf{7 2} \mathbf{h}$ \\
\hline LRH & $3.43 \pm 0.13$ & $2.88 \pm 0.18$ & $2.98 \pm 0.14$ & $2.78 \pm 0.30$ & $2.99 \pm 0.30$ & $3.38 \pm 0.18$ \\
STANDARD & $3.16 \pm 0.29$ & $2.78 \pm 0.32$ & $2.98 \pm 0.29$ & $2.98 \pm 0.55$ & $2.39 \pm 0.21$ & $2.01 \pm 0.22$ \\
CRH & $3.55 \pm 0.06$ & $3.55 \pm 0.15$ & $3.43 \pm 0.19$ & $3.42 \pm 0.16$ & $3.22 \pm 0.21$ & $3.14 \pm 0.14$ \\
HRH & $2.89 \pm 0.36$ & $2.84 \pm 0.28$ & $2.44 \pm 0.26$ & $1.89 \pm 0.24$ & $0.76 \pm 0.15$ & $0.23 \pm 0.06$ \\
\hline
\end{tabular}

The determined transverse strengths of the test specimens confirmed the theoretical assumptions. Generally, curing of the molding mixture occurs due to drying (dehydration). The water contained in the material will pass from the surface of the material into the air stream during drying (external diffusion) and after a certain time when a gradient of moisture in the material is formed, water will diffuse inside the material towards its surface (internal diffusion). The opposite process accords to a sorption mechanism. If the amount of water vapor in the environment does not change, the water content of the material is set to a certain equilibrium value. Equilibrium is decided by a number of factors. Above all, it is the content of water vapor in the surrounding environment, then the temperature and the nature of the solid [15].

The majority effect of relative humidity on the reversibility (rehydration) of the binder system was confirmed. The most significant decrease was obtained in the case of storage in conditions of high humidity and constant temperature (HRH, decrease by $93 \%$ after $72 \mathrm{~h}$ of storage). On the other hand, the change of strengths was minimal under conditions of low relative humidity (LRH), the strength was almost constant during whole experiment.

From the achieved values of the change of transverse strengths, the time until the strengths of the core decrease by $20 \%$ compared to the strength after curing was determined, which was defined as the maximum time for optimal storage of cores from mixtures with inorganic binders cured by heat (Figure 3).

The maximum shelf-life of the test samples has a wide variance depending on the storage conditions, in particular the relative humidity in the environment as mentioned above. The lowest suitable storage time corresponds to the conditions of high relative humidity HRH (21 h), on the contrary, for conditions of low relative humidity LRH the maximum storage time is extended to $104 \mathrm{~h}$. In real practice, this time corresponds to the shelf-life of cores produced by the Resol- $\mathrm{CO}_{2}$ method. If an even longer shelf-life is required, according to the results obtained, it can be extended even further by lowering the ambient temperature. The maximum shelf-life under CRH conditions was $133 \mathrm{~h}$. This correlates with the theory of sorption processes (rehydration mechanism), where one of the key parameters influencing this process is temperature. When the test samples are stored under standard (laboratory) conditions, the maximum shelf-life is $45 \mathrm{~h}$. 


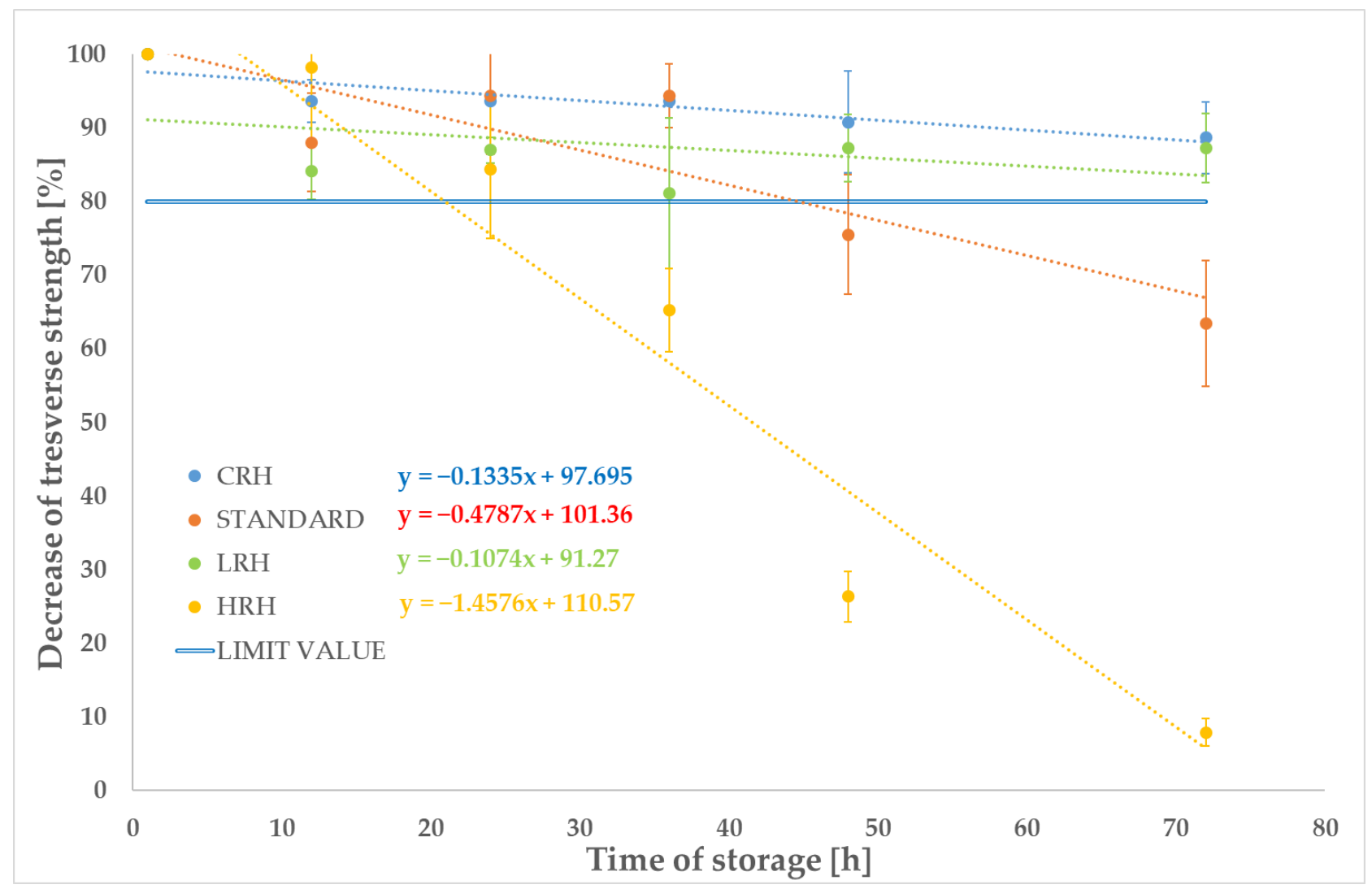

Figure 3. Decrease of transverse strength in \% depending on the time of storage under different storage conditions, average values calculated from three measurements are captured, error bars represent the standard deviation: CRH-Constant relative humidity, low temperature- $\mathrm{RH}=60 \% \pm 5 \%, \mathrm{t}=10{ }^{\circ} \mathrm{C}$; STANDARD—Laboratory ambient conditions- $\mathrm{RH}=60 \%$ $\pm 5 \%, \mathrm{t}=25^{\circ} \mathrm{C}$; LRH-Low relative humidity, constant temperature- $\mathrm{RH}=10 \% \pm 5 \%, \mathrm{t}=25^{\circ} \mathrm{C}$; HRH-High relative humidity, constant temperature- $\mathrm{RH}=90 \% \pm 5 \%, \mathrm{t}=25^{\circ} \mathrm{C}$.

The decrease in mechanical properties of core mixtures can be the source of a number of foundry defects. Even if, for example, the core does not crack during mold preparation prior to casting or during casting, the lower surface strength of the core can cause a number of defects such as the formation of non-metallic inclusions in the casting (flowing of the mixture into the casting). This effect can be determined by wear resistance.

The achieved results of wear resistance of test specimen's stored under defined conditions do not show significant differences between the different storage conditions. According to the specified conditions of the performed measurement, it ranges from 11 to $13 \%$ for the whole storage period. An exception is the HRH storage conditions, where a significant decrease of values of wear resistance occurs between $24 \mathrm{~h}$ and $36 \mathrm{~h}$ of storage. Thus, cores with inorganic binders stored under HRH conditions show a low wear resistance ( $20.46 \%$ after $72 \mathrm{~h}$ of storage), which correlates with the highest moisture increase of $0.83 \%$. If we accept the fact that the main mechanism of wetting is adsorption with respect to the size of the test sample, then the degree of rehydration is given by temperature and pressure (adsorption).

Based on previously obtained results it is known that the main criterion is relative humidity. With increasing partial pressure of humidity $\left(\mathrm{H}_{2} \mathrm{O}\right.$ vapor), the degree of rehydration of the system increases and thus the wear resistance of the test specimens decreases. This fact also correlates with the increase of humidity under LRH conditions (only $0.14 \%$ in $72 \mathrm{~h}$ ). Other storage conditions do not show differences, obtained values of rehydration were $0.29 \%$ (STD) and $0.32 \%(C R H)$.

In further research, the possibilities of simple operational influence on the shelf-life of cores with inorganic heat-cured binders were investigated. A change in the preparation 
conditions of the test specimens was made-shooting pressure was changed from the original 6 bar to 8 bar and 10 bar. The test specimens thus produced were stored under HRH conditions (marked as HRH8 and HRH10) and under standard conditions (STD8; STD10).

The theoretical assumptions of change (decrease) of relative porosity, which was calculated according to Equation (2), with increasing shooting pressure (decrease of grain degree of freedom) were confirmed. The relative porosity of the test specimens produced at 6 bar shooting pressure was $9.71 \%$, while at 8 bar it was $8.35 \%$ (14\% decrease in porosity) and at 10 bar it was $8.17 \%$ (about $16 \%$ decrease compared to the original value). The influence of shooting pressure on mechanical properties (transverse strength) is summarized in Table 4. The values in the table are the average of three measurements, therefore the value of the standard deviation is also given.

Table 4. Transverse strength with standard deviation [MPa] of studied cores stored under defined conditions (different shooting pressures used within the core production): $\mathrm{HRH}-$ High relative humidity, constant temperature- $\mathrm{RH}=90 \% \pm 5 \%$, $\mathrm{t}=25^{\circ} \mathrm{C}$, Shooting pressure 6 bar; HRH8-High relative humidity, constant temperature- $\mathrm{RH}=90 \% \pm 5 \%, \mathrm{t}=25^{\circ} \mathrm{C}$, Shooting pressure 8 bar; $\mathrm{HRH} 10-$ High relative humidity, constant temperature- $\mathrm{RH}=90 \% \pm 5 \%, \mathrm{t}=25^{\circ} \mathrm{C}$, Shooting pressure 10 bar; STD—Laboratory ambient conditions- $\mathrm{RH}=60 \% \pm 5 \%, \mathrm{t}=25{ }^{\circ} \mathrm{C}$, Shooting pressure 6 bar; STD8-Laboratory ambient conditions- $\mathrm{RH}=60 \% \pm 5 \%, \mathrm{t}=25{ }^{\circ} \mathrm{C}$, Shooting pressure 8 bar; STD10—Laboratory ambient conditions$\mathrm{RH}=60 \% \pm 5 \%, \mathrm{t}=25^{\circ} \mathrm{C}$, Shooting pressure 10 bar.

\begin{tabular}{ccccccc}
\hline Conditions & $\mathbf{1 ~ h}$ & $\mathbf{1 2} \mathbf{h}$ & $\mathbf{2 4} \mathbf{h}$ & $\mathbf{3 6} \mathbf{h}$ & $\mathbf{4 8} \mathbf{h}$ & $\mathbf{7 2} \mathbf{h}$ \\
\hline HRH & $2.89 \pm 0.36$ & $2.84 \pm 0.28$ & $2.44 \pm 0.26$ & $1.89 \pm 0.24$ & $0.76 \pm 0.15$ & $0.23 \pm 0.06$ \\
HRH8 & $3.34 \pm 0.20$ & $3.19 \pm 0.03$ & $2.93 \pm 0.18$ & $2.28 \pm 0.43$ & $1.52 \pm 0.18$ & $0.68 \pm 0.08$ \\
HRH10 & $3.69 \pm 0.18$ & $3.40 \pm 0.14$ & $2.94 \pm 0.31$ & $2.31 \pm 0.26$ & $1.32 \pm 0.17$ & $0.69 \pm 0.05$ \\
STD & $3.16 \pm 0.03$ & $2.78 \pm 0.32$ & $2.98 \pm 0.29$ & $2.98 \pm 0.55$ & $2.39 \pm 0.21$ & $2.01 \pm 0.22$ \\
STD8 & $3.98 \pm 0.10$ & $4.08 \pm 0.14$ & $3.93 \pm 0.13$ & $3.44 \pm 0.07$ & $3.35 \pm 0.02$ & $3.34 \pm 0.10$ \\
STD10 & $3.59 \pm 0.05$ & $3.52 \pm 0.05$ & $3.55 \pm 0.05$ & $3.41 \pm 0.30$ & $3.42 \pm 0.04$ & $3.42 \pm 0.05$ \\
\hline
\end{tabular}

The measurement results show a significant positive effect of the shooting pressure on the mechanical properties obtained (column " $1 \mathrm{~h}$ " in Table 4 ).

The increase in shooting pressure and the resulting lower relative porosity has a positive effect on the maximum storage time defined as a $20 \%$ decrease in transverse strength (Figure 4). From the original value of the maximum possible storage time of about $21 \mathrm{~h}$ in the least suitable conditions of high relative humidity (HRH), the storage time was extended to $23.56 \mathrm{~h}$ at a shooting pressure of 8 bar. Using a higher shooting pressure of 10 bar, the storage time was extended to $24.15 \mathrm{~h}$ (an increase of $15 \%$ ). An even more pronounced effect of storage time extension was achieved under standard (laboratory) conditions. At a shooting pressure of 8 bar, the maximum suitable storage time was extended from the original approx. $45 \mathrm{~h}$ to approx. $74 \mathrm{~h}(66 \%$ increase), and at the higher pressure of $10 \mathrm{bar}$, the theoretical maximum storage time was increased more than 6 times to approx. $275 \mathrm{~h}$. Cores stored in this way can be used for casting production for approx. the same period of time as PUCB-based cores used in common practice.

Although these findings are very positive, it should be noted that these are theoretical values. In the case of using a shooting pressure of 10 bar, scrap cores (which were therefore obviously not included in the experiment) appeared during production. This fact can be attributed to the fact that the mixture may have leaked from the core due to the very high shooting pressure. For this reason, a shooting pressure of 10 bar cannot be recommended as a suitable method of extending the shelf-life of the cores thus produced.

The same positive trend was found for other parameters evaluated such as wear resistance (Figure 5) and rewetting determined as moisture content (Figure 6). Although the differences between the values of the individual parameters for the samples prepared with shooting pressures of 8 bar and 10 bar are not as pronounced as the decrease in mechanical properties. The rate of rewetting defined as moisture content decreases with increasing shooting pressure, which correlates with previously found behavior of other inorganic binders [14]. This trend was observed for both storage conditions, differing only 
in absolute values. The reason for this is the reduced relative porosity of the core, in other words, the reduced ability to trap polar compounds in the intergranular spaces of the core and the subsequent dissolution of the inorganic binder.

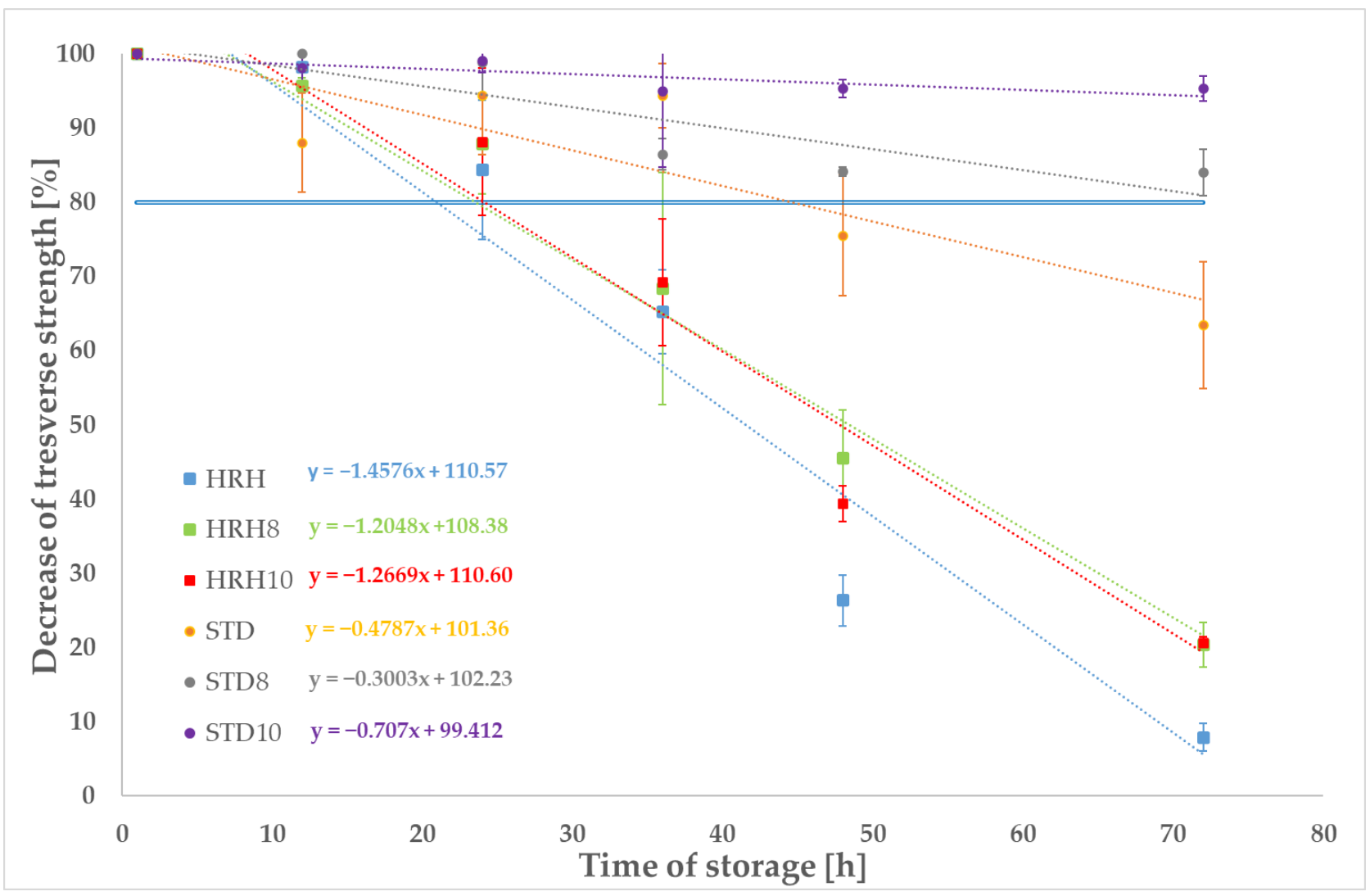

Figure 4. Decrease of transverse strength (in \%) depending on the time of storage under different storage conditions (different shooting pressures used within the core production), average values calculated from three measurements are captured, error bars represent the standard deviation: $\mathrm{HRH}-$ High relative humidity, constant temperature- $\mathrm{RH}=90 \% \pm 5 \%, \mathrm{t}=25{ }^{\circ} \mathrm{C}$, Shooting pressure 6 bar; HRH8 - High relative humidity, constant temperature- $\mathrm{RH}=90 \% \pm 5 \%, \mathrm{t}=25^{\circ} \mathrm{C}$, Shooting pressure 8 bar; HRH10-High relative humidity, constant temperature- $\mathrm{RH}=90 \% \pm 5 \%, \mathrm{t}=25^{\circ} \mathrm{C}$, Shooting pressure 10 bar; STD-Laboratory ambient conditions- $\mathrm{RH}=60 \% \pm 5 \%, \mathrm{t}=25^{\circ} \mathrm{C}$, Shooting pressure 6 bar; STD8-Laboratory ambient conditions- $\mathrm{RH}=60 \% \pm 5 \%, \mathrm{t}=25^{\circ} \mathrm{C}$, Shooting pressure 8 bar; STD10-Laboratory ambient conditions- $\mathrm{RH}=60 \% \pm 5 \%$, $\mathrm{t}=25^{\circ} \mathrm{C}$, Shooting pressure 10 bar.

The wear resistance of the test specimens increased by about $10 \%$ under standard conditions (decrease from $12.04 \%$ to $11.04 \%$ at 8 bar and to $11.09 \%$ at 10 bar) when stored for $72 \mathrm{~h}$. While some differences are evident when stored at high relative humidity (HRH) ( $20.46 \%$ at 6 bar; $18.98 \%$ at 8 bar and $20.64 \%$ at 10 bar), these data are likely to be burdened with significant measurement error as the $72 \mathrm{~h}$ storage time under these conditions is no longer suitable for these inorganic systems and the test specimens are significantly subject to rehydration, thus significantly affecting these values.

In the last phase of the experiment, the effect of storage conditions on the surface quality from the cores was also investigated. From the results of the measurements (see Table 5), it can be seen that the differences in the measured surface roughness values are very small and it is therefore not possible to clearly determine which surface achieved the highest quality. If we really have to look for trends within such a tight range of measured values, then it could be said that the surfaces of the cast samples using cores stored at standard conditions have overall slightly higher Ra $(3.59-4.09 \mu \mathrm{m})$ and $\mathrm{Rz}(17.20-18.56 \mu \mathrm{m})$ values and, conversely, the surfaces from cores samples stored under high relative humidity conditions have slightly lower $\mathrm{Ra}(2.99-3.28 \mu \mathrm{m})$ and $\mathrm{Rz}(14.21-15.41 \mu \mathrm{m})$ values. However, 
considering the really slight differences, it should be noted that, independently of the storage conditions (assuming the maximum shelf-life is not exceeded) and the manufacturing parameters (varying shooting pressure), the surfaces from the cores show approximately the same surface quality. This factor is therefore not limiting in terms of shelf-life.

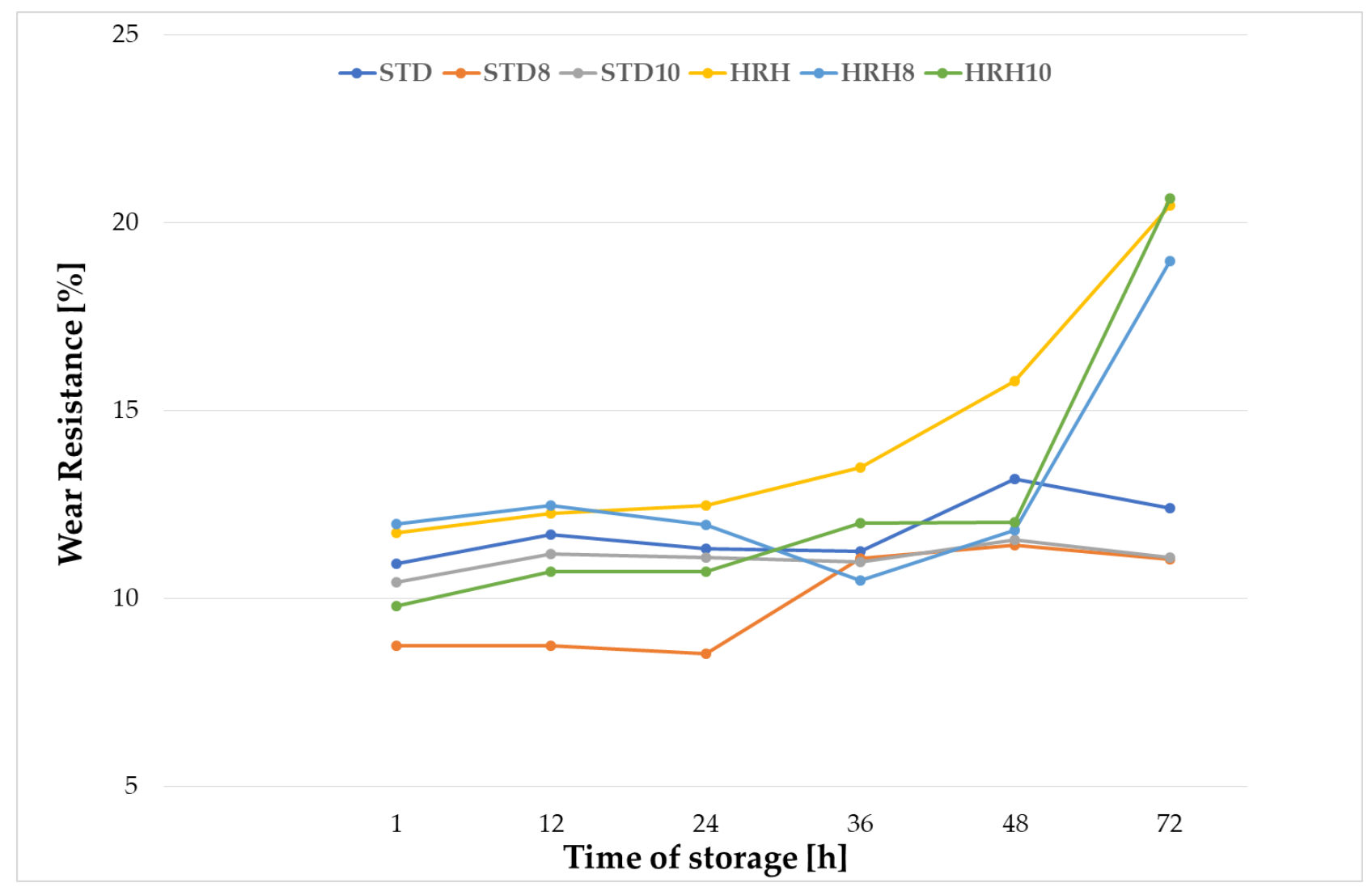

Figure 5. Wear resistance of cores depending on the time of storage under different storage conditions (different shooting pressures used within the core production): STD—Laboratory ambient conditions- $\mathrm{RH}=60 \% \pm 5 \%$, $\mathrm{t}=25{ }^{\circ} \mathrm{C}$, Shooting pressure 6 bar; STD8-Laboratory ambient conditions-RH $=60 \% \pm 5 \%, \mathrm{t}=25{ }^{\circ} \mathrm{C}$, Shooting pressure 8 bar; STD10Laboratory ambient conditions- $\mathrm{RH}=60 \% \pm 5 \%, \mathrm{t}=25^{\circ} \mathrm{C}$, Shooting pressure 10 bar; HRH-High relative humidity, constant temperature- $\mathrm{RH}=90 \% \pm 5 \%, \mathrm{t}=25{ }^{\circ} \mathrm{C}$, Shooting pressure 6 bar; HRH8-High relative humidity, constant temperature- $\mathrm{RH}=90 \% \pm 5 \%, \mathrm{t}=25^{\circ} \mathrm{C}$, Shooting pressure 8 bar; HRH10-High relative humidity, constant temperature$\mathrm{RH}=90 \% \pm 5 \%, \mathrm{t}=25^{\circ} \mathrm{C}$, Shooting pressure 10 bar.

Table 5. Values of surface roughness with standard deviation of tested casting: HRH-High relative humidity, constant temperature- $\mathrm{RH}=90 \% \pm 5 \%, \mathrm{t}=25{ }^{\circ} \mathrm{C}$, Shooting pressure 6 bar; HRH8-High relative humidity, constant temperature- $\mathrm{RH}=90 \% \pm 5 \%, \mathrm{t}=25^{\circ} \mathrm{C}$, Shooting pressure 8 bar; HRH10-High relative humidity, constant temperature$\mathrm{RH}=90 \% \pm 5 \%, \mathrm{t}=25^{\circ} \mathrm{C}$, Shooting pressure 10 bar; STD-Laboratory ambient conditions- $\mathrm{RH}=60 \% \pm 5 \%, \mathrm{t}=25{ }^{\circ} \mathrm{C}$, Shooting pressure 6 bar; STD8-Laboratory ambient conditions- $\mathrm{RH}=60 \% \pm 5 \%, \mathrm{t}=25^{\circ} \mathrm{C}$, Shooting pressure 8 bar; STD10-Laboratory ambient conditions- $\mathrm{RH}=60 \% \pm 5 \%, \mathrm{t}=25^{\circ} \mathrm{C}$, Shooting pressure 10 bar.

\begin{tabular}{ccccccc}
\hline Conditions & STD & HRH & STD8 & HRH8 & STD10 & HRH10 \\
\hline $\operatorname{Ra}[\mu \mathrm{m}]$ & $3.59 \pm 0.71$ & $3.15 \pm 1.00$ & $4.09 \pm 0.98$ & $3.28 \pm 0.69$ & $3.89 \pm 0.93$ & $2.99 \pm 0.63$ \\
$\operatorname{Rz}[\mu \mathrm{m}]$ & $17.20 \pm 3.10$ & $15.11 \pm 4.89$ & $18.56 \pm 4.03$ & $15.41 \pm 2.73$ & $17.85 \pm 4.73$ & $14.21 \pm 2.88$ \\
\hline
\end{tabular}




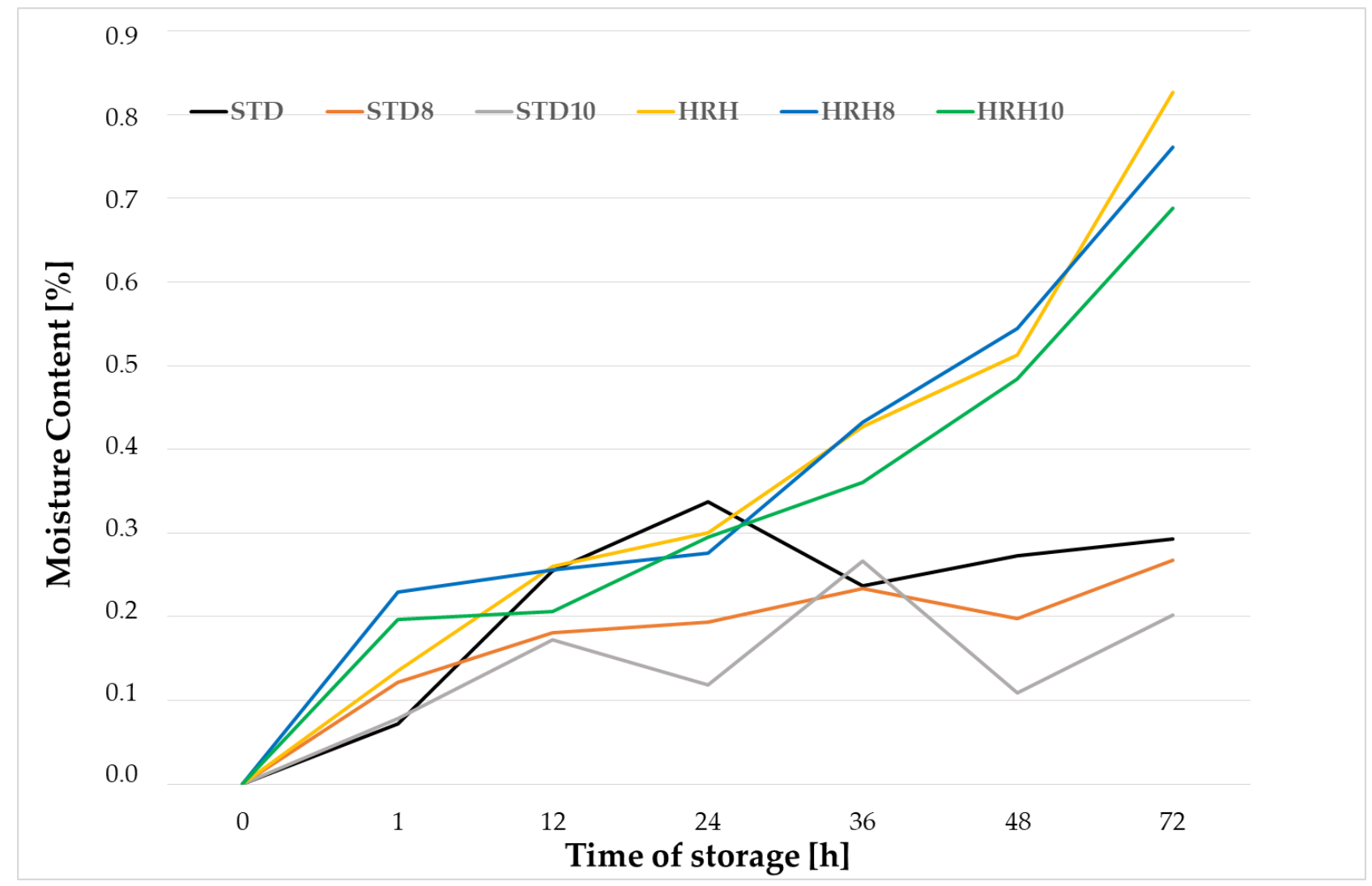

Figure 6. Moisture content of cores depending on the time of storage under different storage conditions (different shooting pressures used within the core production): STD—Laboratory ambient conditions- $\mathrm{RH}=60 \% \pm 5 \%, \mathrm{t}=25^{\circ} \mathrm{C}$, Shooting pressure 6 bar; STD8-Laboratory ambient conditions- $\mathrm{RH}=60 \% \pm 5 \%, \mathrm{t}=25{ }^{\circ} \mathrm{C}$, Shooting pressure 8 bar; STD10Laboratory ambient conditions- $\mathrm{RH}=60 \% \pm 5 \%, \mathrm{t}=25^{\circ} \mathrm{C}$, Shooting pressure $10 \mathrm{bar}$; HRH-High relative humidity, constant temperature- $\mathrm{RH}=90 \% \pm 5 \%, \mathrm{t}=25^{\circ} \mathrm{C}$, Shooting pressure 6 bar; HRH8-High relative humidity, constant temperature- $\mathrm{RH}=90 \% \pm 5 \%, \mathrm{t}=25^{\circ} \mathrm{C}$, Shooting pressure 8 bar; HRH10-High relative humidity, constant temperature$\mathrm{RH}=90 \% \pm 5 \%, \mathrm{t}=25^{\circ} \mathrm{C}$, Shooting pressure 10 bar.

\section{Conclusions}

An important limiting factor for the further spread of new types of inorganic binders in the casting industry is the limited shelf-life of the material when stored in ambient or humid environments. Under normal production conditions in foundries, cores often cannot be produced "just in time" and need to be properly stored for several hours before use. Due to the curing mechanism of the system with inorganic binders (reversible process), the relative humidity of the environment has emerged as a key factor for maintaining optimal storage conditions for the cores. By adjusting the appropriate storage conditions, the shelf life of the cores can be extended from $24 \mathrm{~h}$ to tens of days, which in normal foundry practice corresponds to the shelf-life of cores produced by the COLD-BOX Amin (PUCB) technology.

If favorable storage conditions cannot be maintained, the stability of the cores during storage can also be influenced by adjusting the shooting pressure. Increasing the shooting pressure from 6 bar to 8 bar will reduce the relative porosity of the cores, which has a positive effect on the transverse strength of the cores and wear resistance, slowing down the rehydration of the binder and thus prolonging the shelf life of the cores. However, further increases in ejection pressure (to $10 \mathrm{bar}$ ) are problematic and cannot be recommended. Exceeding a certain shooting pressure level can cause fluctuations in the quality of the cores produced, mainly in transverse strength values. If the maximum shelf-life is not exceeded the effect of different storage conditions on the resulting surface quality of the castings is minimal. 
Author Contributions: Conceptualization, P.L., I.V. and K.J.; methodology, I.N. and T.O.; software, M.G. and F.R.; validation, T.O., V.M. and M.F.; formal analysis, V.M., J.B. (Josef Bradáč) and J.B. (Jaroslav Beňo); investigation, V.M., T.O. and N.N.; resources J.B. (Jaroslav Beňo); data curation, I.K., M.G. and N.N.; writing — original draft preparation J.B. (Jaroslav Beňo); writing-review and editing K.J., I.V., V.M., M.F., K.D. and J.B. (Josef Bradáč); visualization, V.M. and N.N.; supervision, P.L.; project administration, V.M.; funding acquisition, P.L., J.B. (Josef Bradáč) and M.F. All authors have read and agreed to the published version of the manuscript.

Funding: This research was funded by the project No. CZ.02.1.01/0.0/0.0/17_049/0008399 from the EU and CR financial funds provided by the Operational Programme Research, Development and Education, Call 02_17_049 Long-Term Intersectoral Cooperation for ITI, Managing Authority: Czech Republic-Ministry of Education, Youth and Sports. This work was supported by the Doctoral grant competition VSB-Technical University of Ostrava, reg. no. CZ.02.2.69/0.0/0.0/19_073/0016945 within the Operational Programme Research, Development and Education, under project DGS/ TEAM/2020-037 "Possibilities of influencing the collapsibility of core mixtures for use in technologies for the production of castings from aluminium alloys and magnesium alloys". This work was carried out in the support of projects of "Student Grant Competition" numbers SP2021/39 a SP2021/41.

Institutional Review Board Statement: Not applicable.

Informed Consent Statement: Not applicable.

Data Availability Statement: The data presented in this study are available on request from the corresponding author. The funders had no role in the design of the study; in the collection, analyses, or interpretation of data; in the writing of the manuscript; or in the decision to publish the results generated during the study.

Conflicts of Interest: The authors declare no conflict of interest.

\section{References}

1. Petržela, L. Vodní Sklo $\mathrm{CO}_{2}$ Proces. Czechoslovakia Patent 81931, 12 December 1947.

2. Dobosz, S.; Jelínek, P.; Major-Gabryś, K. Development tendencies of molding and core sands. China Foundry $2011,8,438-446$.

3. Polzin, H. Inorganic Binders for Mould and Core Production in the Foundry, 1st ed.; Fachverlag Schiele und Schön GmbH: Berlin, Germany, 2014; pp. 105-120.

4. Josan, A.; Pinca-Bretotean, C.; Ratiuc, S. Management of the regeneration process of the moulding mixtures in order to reduce the costs of the foundry type industrial enterprises. Mater. Today Proc. 2021, 45, 4161-4165. [CrossRef]

5. Fan, Z.T.; Huang, N.Y.; Dong, X.P. In house reuse and reclamation of used foundry sands with sodium silicate binder. Int. J. Cast Met. Res. 2004, 17, 51-56. [CrossRef]

6. Brown, J.R. Foseco Ferrous Foundryman's Handbook, 1st ed.; Butterworth-Heinemann: Oxford, UK, 2000 ; pp. 167-213.

7. Jelínek, P. Inorganic binders make way to foundries. Slévárenství 2012, 60, 66-70.

8. Högl, J. INOTEC ${ }^{\circledR}$ New Inorganic Binder for Foundry Serial Production. In Proceedings of the Congresso Assofond, Vicenza, Italy, 20 October 2012; Congresso Assofond: Vicenza, Italy, 2012; p. 29.

9. Stachowicz, M.; Granat, K.; Nowak, D.; Haimann, K. Effect of hardening methods of moulding sands with water glass on structure of bonding. Arch. Foundry Eng. 2010, 10, 123-128.

10. Song, L.; Liu, W.; Li, Y. Humidity-resistant inorganic binder for sand core making in foundry practice. China Foundry 2019, 16, 267-271. [CrossRef]

11. Voigt, P.; Bischoff, U.; Ristau, B.; Georgi, B.; Sil, H.J.; Lustig, C. Use of new inorganic binders in the production of aluminum cylinder heads. Cast. Plant Technol. 2006, 2, 16-21.

12. Löchte, K.; Böhm, R. Cordis, The inorganic binder system-Properties and experience. Cast. Plant. Technol. Int. 2005, 3, 6-11.

13. Vykoukal, M.; Burian, A.; Přerovská, M. Geopol ${ }^{\circledR}$. The innovated environment Friendly Inorganic Binder System. Arch. Foundry Eng. 2019, 19, 109-116.

14. Beňo, J.; Adámková, E.; Mikšovský, F.; Jelínek, P. Development of composite salt cores for foundry applications. Mater. Tehnol. Mater. Technol. 2015, 49, 619-623. [CrossRef]

15. Bird, R.B.; Stewart, W.E.; Lightfoot, E.N. Transport Phenomena, 1st ed.; John Wiley \& Sons, Inc.: New York, NY, USA, 1960; pp. 679-688. 